\title{
Successful endoscopic treatment of spontaneous perforation of the common hepatic duct
}

Perforations of the biliary tract usually occur in the gallbladder as a complication of acute cholecystitis. Spontaneous perforation of the extrahepatic biliary tract is a rare entity, reported usually in infants and associated with congenital anomalies. Here we report the first case of spontaneous perforation of a common hepatic duct, treated successfully with percutaneous drainage and endoscopic stenting. A 67-year-old man presented to hospital with a 1-week history of upper abdominal discomfort, nausea, and fever. Laboratory tests revealed mild leukocytosis, C-reactive protein $265 \mathrm{mg} / \mathrm{L}(<10 \mathrm{mg} / \mathrm{L})$, and total bilirubin $79 \mu \mathrm{mol} / \mathrm{L}(5-25 \mu \mathrm{mol} / \mathrm{L})$. The other liver chemistry tests and plasma amylase activity were within normal limits. Blood cultures showed growth of Escherichia coli.

An abdominal computed tomographic (CT) scan revealed a large fluid collection approximately $10 \mathrm{~cm}$ in diameter in the hepatic hilar area ( $\bullet$ Fig. 1).

The collection was drained on the same day and the fluid proved to be bile. Endoscopic retrograde cholangiopancreatography (ERCP) revealed contrast leakage from the common hepatic duct ( $\bullet$ Fig. 2). A $10-\mathrm{Fr}, 10-\mathrm{cm}$ plastic stent was inserted into the bile ducts with the distal end of the stent above the leakage. Otherwise, the patient was treated conservatively and recovery was uneventful. At repeat ERCP 3 months later, the stent was removed and the cholangiogram showed no leakage or strictures ( Fig. 3).

Eighteen months later, the patient was free of biliary symptoms.

Spontaneous perforation of the biliary tract is a rare entity; in adults it is often diagnosed at a postmortem. Although several etiological factors such as bile duct stones, tumours, infections, and ischemia have been proposed, $70 \%$ of the cases are related to stones [1]. Traditionally, the treatment of choice in bile duct perforations has been surgery [2,3], but with the recent advancements in stenting [4] and lessons learned from iatrogenic lesions [5], endoscopic treatment should be considered in stable patients.

Endoscopy_UCTN_Code_CCL_1AZ_2AN

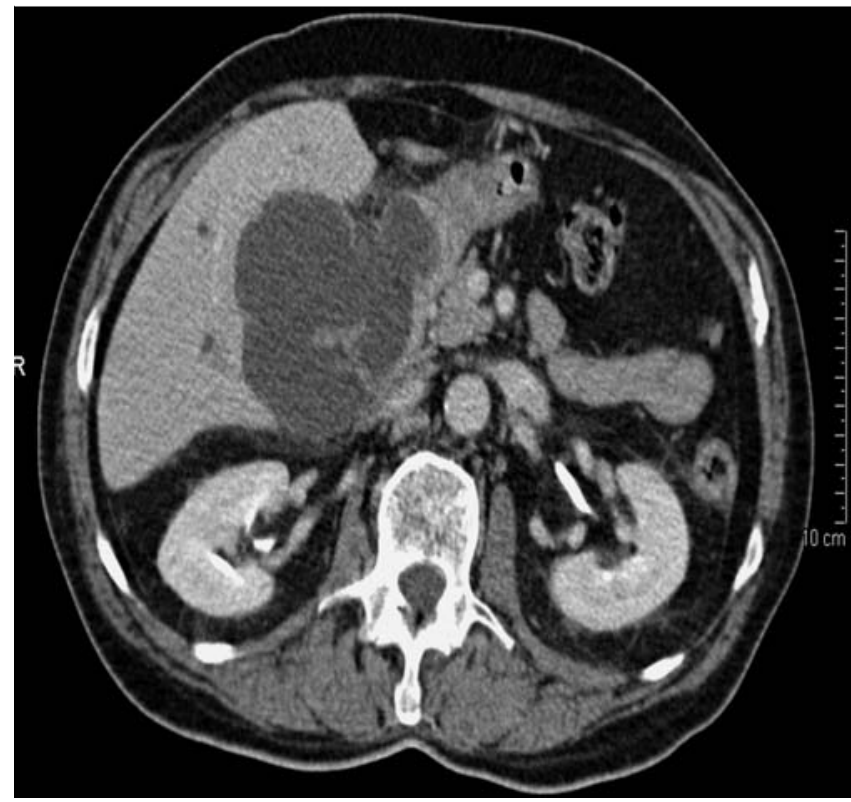

Fig. 1 A large fluid collection, approximately $10 \mathrm{~cm}$ in diameter, in the hepatic hilar area, visualized on an abdominal computed tomographic scan.

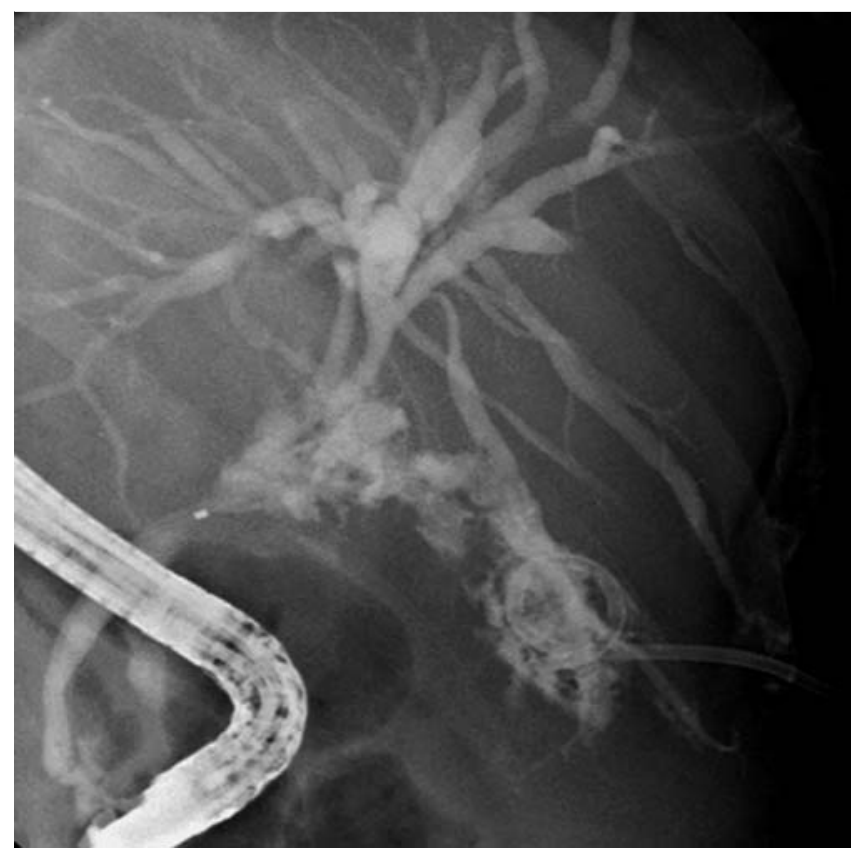

Fig. 2 Endoscopic retrograde cholangiography showing contrast leakage from the common hepatic duct.

\section{J. Karvonen ${ }^{1}$, R. Gullichsen ${ }^{2}$,}

P. Salminen², S. Laine², J. M. Grönroos ${ }^{2,3}$ Department of Surgery, Loimaa District Hospital, Loimaa, Finland

2 Department of Surgery, University of Turku, Turku, Finland

${ }^{3}$ Emergency Department, University of Turku, Turku, Finland

\section{References}

1 Piotrowski JJ, Van Stiegmann G, Liechty RD. Spontaneous bile duct rupture in pregnancy. HPB Surg 1990; 2: 205-209

2 Talwar N, Andley M, Ravi B et al. Spontaneous biliary tract perforations: an unusual cause of peritonitis in pregnancy. Report of two cases and review of literature. World J Emerg Surg 2006; 1: 21 


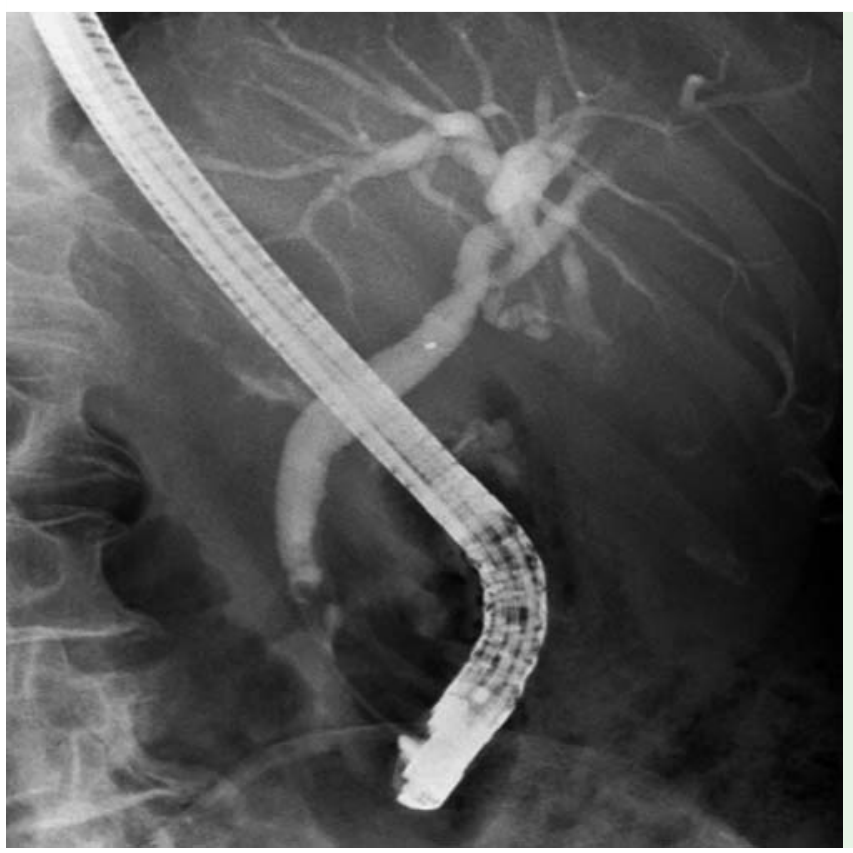

Fig. 3 Repeat endoscopic retrograde cholangiopancreatography 3 months later showing neither leakage nor strictures.
3 Rege SA, Lambe S, Sethi $\mathrm{H}$ et al. Spontaneous common bile duct perforation in adult: a case report and review. Int Surg 2002; 87: $81-82$

4 Gronroos JM. How to avoid unnecessary laparotomies in iatrogenic bile duct injuries? Am J Surg 2009; 197: 133-134

5 Karvonen J, Gullichsen R, Laine $S$ et al. Bile duct injuries during laparoscopic cholecystectomy: primary and long-term results from a single institution. Surg Endosc 2007; 21: $1069-1073$

\section{Bibliography}

DOI 10.1055/s-0029-1214926

Endoscopy 2009; 41: E224-E225

(c) Georg Thieme Verlag KG Stuttgart · New York . ISSN 0013-726X

\section{Corresponding author}

Dr. J. Karvonen

Loimaa District Hospital

Seppälänkatu 15-17

PB 17, FIN-32201

Loimaa

Finland

Fax: +358-2-3143321

jukka.karvonen@tyks.fi 